\title{
Effect of Sleep State on Chest Distortion and on the Ventilatory Response to $\mathrm{CO}_{2}$ in Neonates
}

\author{
MARIA DAVI, KORAVANGATTU SANKARAN, MARILYN MACCALLUM, DON CATES, AND \\ HENRIQUE RIGATTO
}

Department of Pediatrics, University of Manitoba, Winnipeg, Manitoba, Canada

\begin{abstract}
Summary
The authors studied 10 preterm infants (birth weight, $1840 \pm$ $270 \mathrm{~g}$; gestational age, $31 \pm 3 \mathrm{wk}$ ) and 10 term infants (birth weight, $3700 \pm 320 \mathrm{~g}$; gestational age, $40 \pm 1$ wk) to evaluate the effect of sleep state on chest distortion and on the ventilatory response to $\mathrm{CO}_{2}$. Sleep state was defined on the basis of body movements, eye movements, and electroencephalogram. Chest distortion was assessed using micromagnetometers applied to the rib cage and abdomen. After a control period breathing $21 \% \mathrm{O}_{2}$ in each sleep state, infants were given $3 \% \mathrm{CO}_{2}$ to breathe. Respiratory minute volume and frequency, tidal volume, alveolar $\mathrm{PCO}_{2}$ and $\mathrm{PO}_{2}, \mathrm{CO}_{2}$ response curves, and chest distortion were measured. It was found that: 1) respiratory minute volume increased and $\mathrm{PaCO}_{2}$ decreased during REM as compared to non-REM sleep in preterm and term infants $(P<0.05) ; 2)$ chest distortion was not affected by sleep state, but was more frequent in preterm than in term infants $(P<0.02) ; 3)$ the ventilatory response to $\mathrm{CO}_{2}$ was not affected by sleep state $(P>0.4)$; and 4$) \mathrm{CO}_{2}$ did not affect chest distortion $(P>0.1)$. These findings indicate: 1$)$ contrary to previous observations, chest distortion is independent of sleep state; and 2) the ventilatory response to $\mathrm{CO}_{2}$ was not affected by sleep state. The authors suggest that the higher prevalence of chest distortion in preterm infants is related to their highly compliant chest wall rather than to differences in sleep state.
\end{abstract}

\section{Speculation}

Teleologically, almost anything increases with gestational age. Chest stability, non-REM sleep, ventilatory response to $\mathrm{CO}_{2}$, and prevalence of regular breathing, all increase with maturation. The authors would like to speculate, therefore, that the differences in chest distortion are immaturity rather than sleep state dependent. The authors believe that distortion is present not only because the rib cage muscles are weak or chest wall reflexes inefficient, but also because the bone structure of the rib cage is highly cartilagenous and cannot afford stability.

It has long been known that the respirator pattern is more regular during non-REM than during REM sleep. Only recently, however, the physiologic differences between these two sleep states have been more thoroughly investigated $(2,4,5,7,8,14,16,19$, $20)$. In this regard, two provocative observations were made. First, it was suggested that the clinical "see-saw" breathing of preterm and, less frequently, term infants, with indrawing of the rib cage and outward displacement of the abdomen, is characteristic of REM sleep (17). This paradoxical movement of rib cage and abdomen has also been named "chest distortion," because the rib cage moves inwards instead of outwards during inspiration. Second, the ventilatory response to $\mathrm{CO}_{2}$ was decreased during REM as compared to non-REM sleep in adult dogs (19). The issue became controversial, however, when one study in newborn primates showed similar (13) and another in newborn infants showed a decreased (6) response to $\mathrm{CO}_{2}$ during REM sleep. Because chest distortion seems to be associated with increased work of breathing (11), it was hypothesized that REM sleep might decrease the ventilatory response to $\mathrm{CO}_{2}$, if chest distortion is indeed present during REM sleep only. This study was designed, therefore, to define the effect of sleep state on chest distortion and on the ventilatory response to $\mathrm{CO}_{2}$.

\section{SUBJECTS AND METHODS}

\section{SUBJECTS}

Ten healthy preterm infants were studied (birth weight, 1840 $\pm 270 \mathrm{~g}$; gestation age, $31 \pm 3 \mathrm{wk}$ ) and 10 term infants (birth weight, $3700 \pm 320 \mathrm{~g}$; gestational age, $40 \pm 1 \mathrm{wk}$ ). Postnatal ages were $21 \pm 15$ and $3 \pm 2$ days, respectively. In preterm infants, there were 8 females and 2 males; in term infants, 2 females and 7 males.

\section{METHODS}

The system to measure ventilation has been described previously $(22,23,25)$. Briefly the infant breathed through nostril adaptors of a nosepiece and added (expiration) or subtracted (inspiration) flow from a constant background flow. The flow signal was integrated to give volume.

We monitored breath-to-breath $\mathrm{PO}_{2}$ and $\mathrm{PCO}_{2}$ using a catheter (PE-20) connected to a vacuum pump (Welch Scientific Co., Duo Seal, Model 1400). The 95\% rise time of the $\mathrm{CO}_{2}$ analyzer (Beckman LB-2) was $0.14 \mathrm{sec}$ and that of the $\mathrm{O}_{2}$ analyzer (Beckman OM-11) was $0.18 \mathrm{sec}$. To obtain appropriate $\mathrm{O}_{2}$ concentration (in this study $21 \% \mathrm{O}_{2}$ ), $\mathrm{O}_{2}$ and $\mathrm{N}_{2}$ were mixed in a low flow blender (Bird Corp., Model 9992901). This mixture was then fed into a second blender where $3 \% \mathrm{CO}_{2}$ could be added (25).

Chest distortion was measured using magnetometers applied to the rib cage and abdomen (17). The exciter coils were placed in the midline at the level of the fourth intercostal space and just above the umbilicus, with the receiving coils placed directly opposite on the posterior surface. The signal voltage was linear for the distance ranges being studied. Sleep state was monitored according to standardized methods (21). EEG was monitored with electrodes placed in the $\mathrm{C}_{4}-\mathrm{A}_{1}$ position (21). The EOG was recorded from the upper outer canthus of the left eye and the lower outer canthus of the right eye and referred to the left ear lobe. Non-REM and REM sleep were characterized according to previous recommendation (10). Respiratory pattern was not used as one of the criterion. The rationale for this is that it makes no sense to ask what the respiratory behavior is during the two types of sleep state if such behavior is used to define sleep state. Accordingly, non-REM sleep was defined by occasional slow body movements, no eye movements, and "tracé alternant" on EEG. REM sleep was defined by the presence of jerky movements of the body, eye movements detected visually and on record (EOG) and irregular lower voltage on EEG. 


\section{PROCEDURE}

Infants were studied on the Ohio Neonatal Intensive Care Unit in a neutral thermal environment (skin abdominal temperature was $36.5 \pm 0.003^{\circ} \mathrm{C}$ ). After appropriate placement of the EEG, $E K G$, and EOG electrodes and magnetometers, infants were allowed to breathe $21 \% \mathrm{O}_{2}$ for $3-5 \mathrm{~min}$ in each sleep state. They were then given $3 \% \mathrm{CO}_{2}$ to breathe for $5 \mathrm{~min}$. During administration of $\mathrm{CO}_{2}, \mathrm{PaO}_{2}$ was kept within $\pm 5 \mathrm{~mm} \mathrm{Hg}$ of control $\mathrm{O}_{2}$ breathing. A representative tracing is shown in Figure 1.

\section{ANALYSIS}

Respiratory minute volume and frequency, tidal volume, alveolar $\mathrm{PCO}_{2}$ and $\mathrm{PO}_{2}$, and chest distortion during the two sleep states, before and after administration of $\mathrm{CO}_{2}$, were determined. Measurements were made between 3 and 5 min while the infant was breathing $21 \% \mathrm{O}_{2}$ or $21 \% \mathrm{O}_{2}+3 \% \mathrm{CO}_{2}$, in a particular sleep state. Maximal response to $\mathrm{CO}_{2}$ was always obtained by $3 \mathrm{~min}$, corroborating our previous observations $(23,24)$. The $\mathrm{CO}_{2}$ response curve was calculated from minute ventilation and $\mathrm{PaCO}_{2}$ while the infant was breathing $21 \% \mathrm{O}_{2}$ and while breathing $21 \% \mathrm{O}_{2}+$ $3 \% \mathrm{CO}_{2}$.

The paired $t$-test was used to characterize the significance of the difference between non-REM vs. REM sleep in the same infants. The $\chi^{2}$ analysis was used to assess the significance of the differences in the prevalence of chest distortion in preterm vs. term infants.

\section{RESULTS}

Our findings are shown in Tables 1 and 2. Respiratory minute volume increased and $\mathrm{PaCO}_{2}$ decreased when preterm and term infants switched from non-REM to REM sleep $(P<0.05)$. This means that alveolar ventilation increased during REM sleep. The changes in ventilation were predominantly due to changes in respiratory frequency with little change in tidal volume.

Sleep state did not affect the prevalence of chest distortion $(P$ $>0.1)$, but gestational age did $(P<0.02)$. Preterm infants distorted more frequently than term infants. In preterm infants, chest distortion was observed in 7 of 10 and in 9 of 10 infants during non-REM and REM sleep, respectively $(P>0.1)$. In term infants, 2 of 10 and 4 of 10 showed chest distortion during non-REM and REM sleep, respectively $(P>0.1)$. This prevalence of distortion did not change with $\mathrm{CO}_{2}$ administration $(P>0.1$, Fig. 2). Also, the administration of $\mathrm{CO}_{2}$, within the limits outlined in this study, did not affect sleep state.

The slope of the ventilatory response to $\mathrm{CO}_{2}$ was not different during non-REM and REM sleep, both in preterm and term infants $(P>0.4$, Figs. 3 and 4$)$. The intercept, however, was shifted to the left during REM sleep $(P<0.005)$. In preterm infants, slopes were $0.050 \pm 0.009$ and $0.039 \pm 0.007 \mathrm{liter} / \mathrm{min} /$ $\mathrm{kg} / \mathrm{mm} \mathrm{Hg} \mathrm{PaCO}$, the corresponding intercepts being $40 \pm 2$ and $35 \pm 1 \mathrm{~mm} \mathrm{Hg} \mathrm{PaCO}$, during the non-REM and REM sleep, respectively. In term infants, slopes were $0.045 \pm 0.011$ and 0.038 $\pm 0.007 \mathrm{liter} / \mathrm{min} / \mathrm{kg} / \mathrm{mm} \mathrm{Hg} \mathrm{PaCO}$, the corresponding intercepts being $39 \pm 1$ and $37 \pm 1 \mathrm{~mm} \mathrm{Hg} \mathrm{PaCO}$ during the non-REM and REM sleep, respectively.

\section{DISCUSSION}

It was found that, 1) sleep state did not affect chest distortion or the ventilatory response to $\mathrm{CO}_{2}$, and 2) administration of $\mathrm{CO}_{2}$ did not change sleep state or the prevalence of chest distortion. Because chest distortion was more frequent in preterm than in

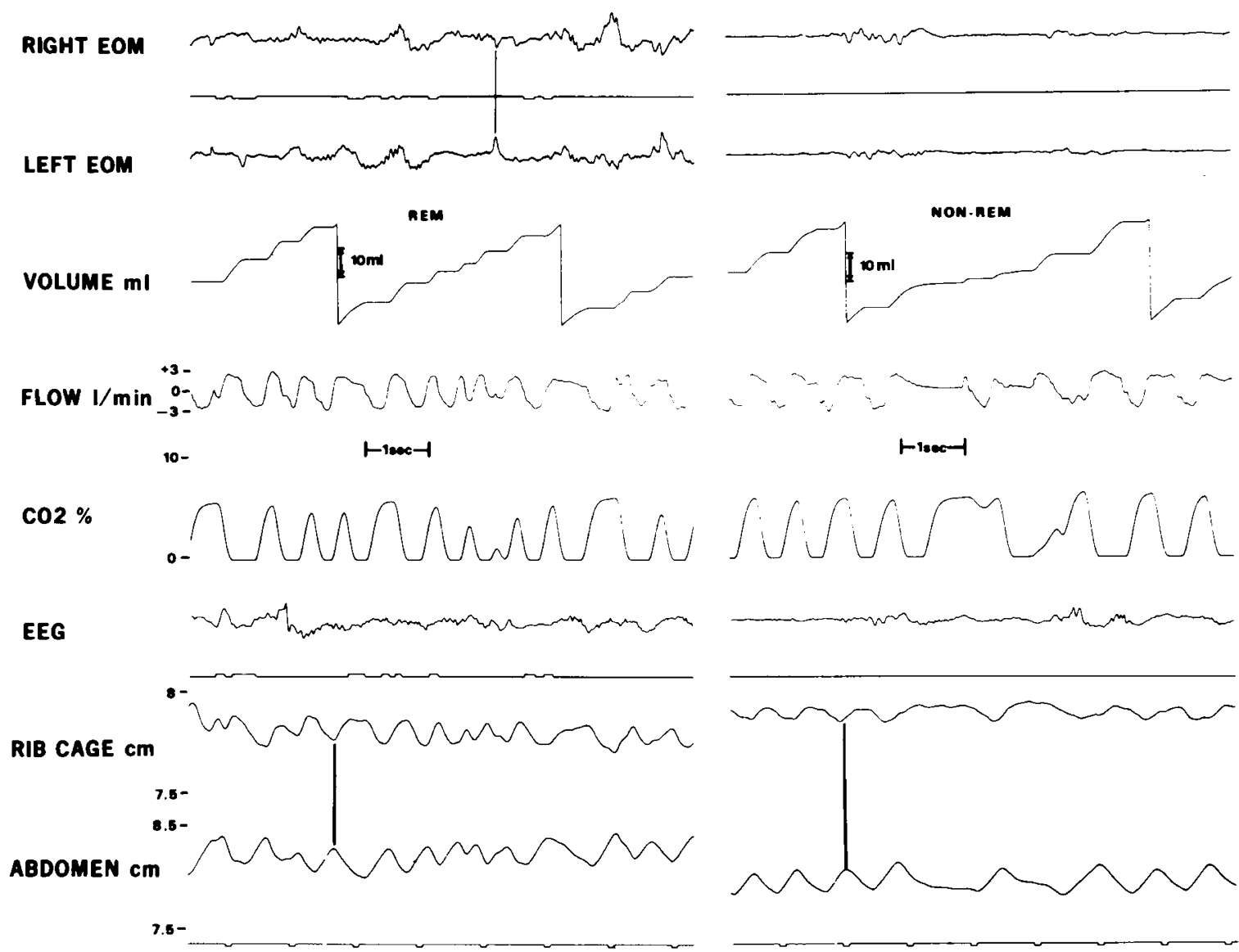

Fig. 1. Representative tracing in one preterm infant (No. 4, birth wt, $1460 \mathrm{~g}$; gestational age, $28 \mathrm{wk}$ ) during REM and non-REM sleep. Note that chest distortion, i.e., paradoxical movements of rib cage and abdomen, is present during both sleep states. 


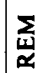

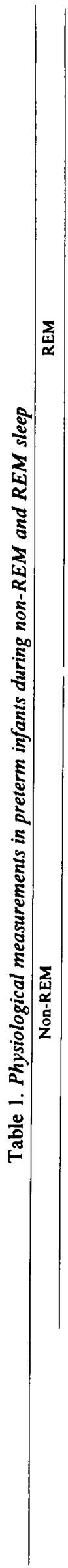

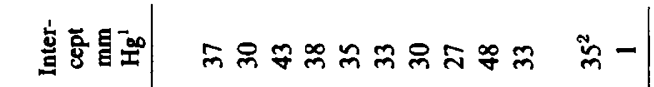

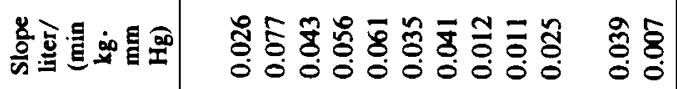

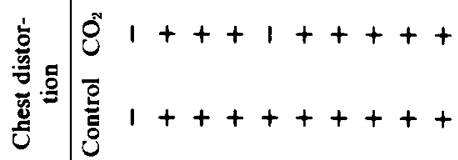

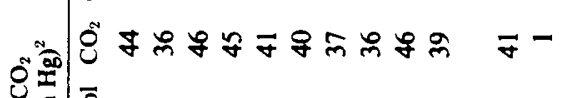

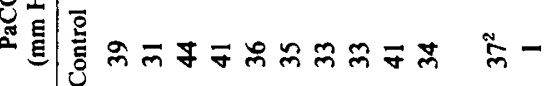

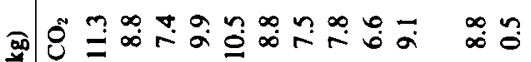

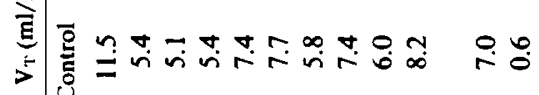

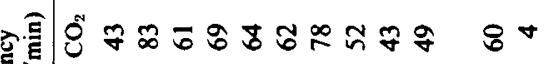
要卷

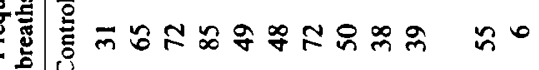

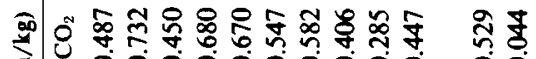
$>$ है

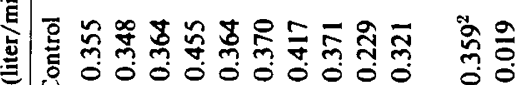

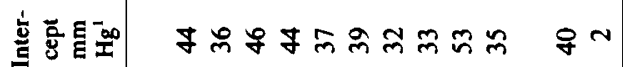

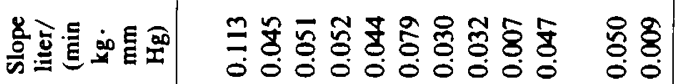
递

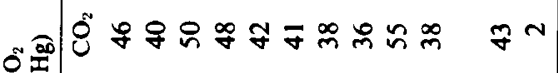

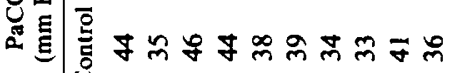
की छิ

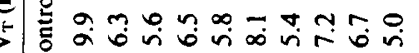

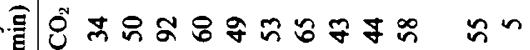
氖商

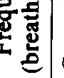

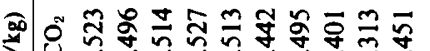
$\rightarrow$ 离

密 -

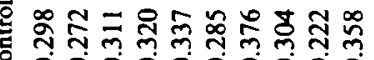

聯 $\infty \backsim a n m a m=\infty-n$

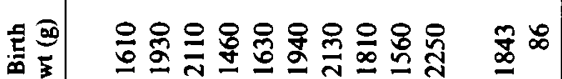

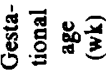

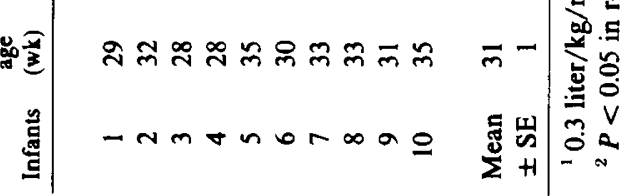

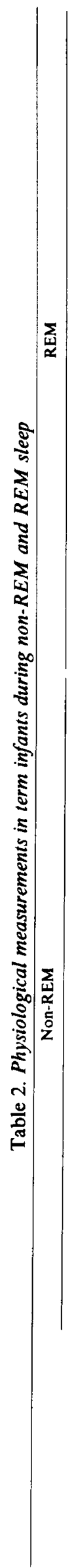

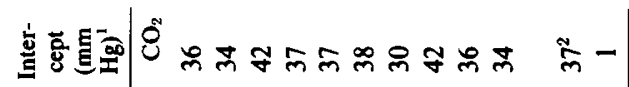

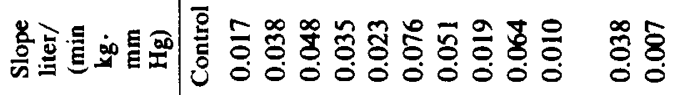

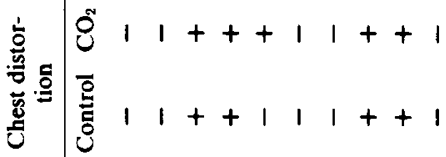

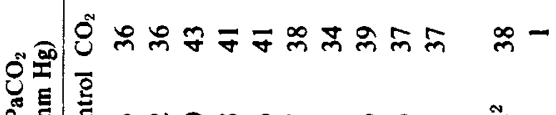

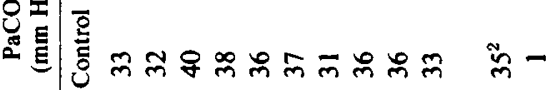

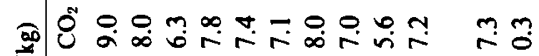
हे

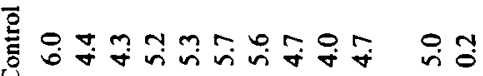

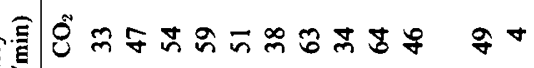

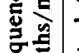

蛋密

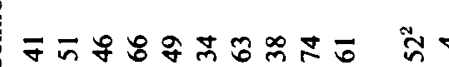

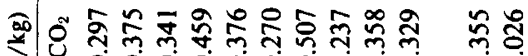
$>$ 年

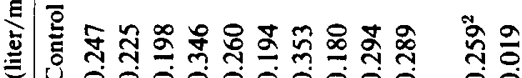

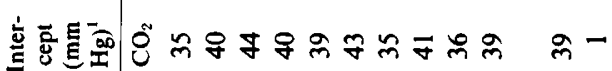

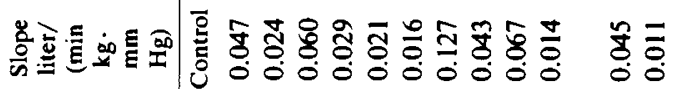
离

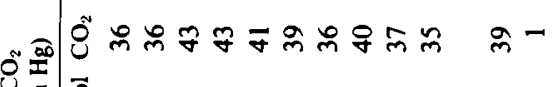

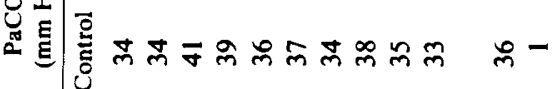

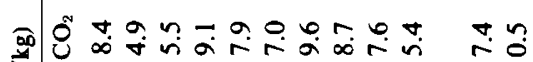
हे $\overline{0}$

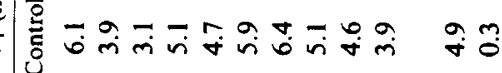

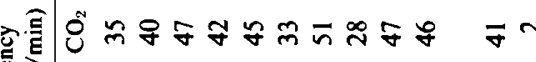

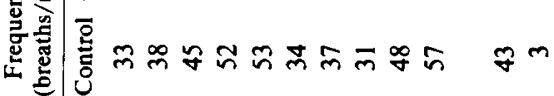

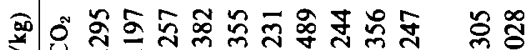

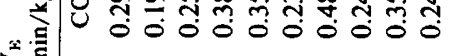

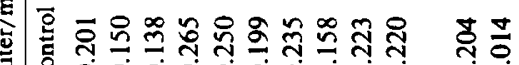
ปั

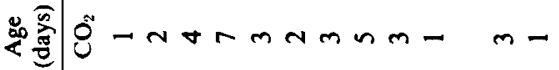

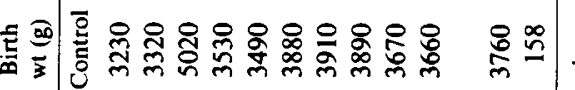

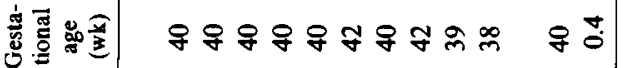

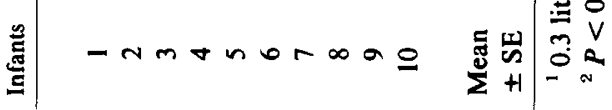


PRETERM INFANTS

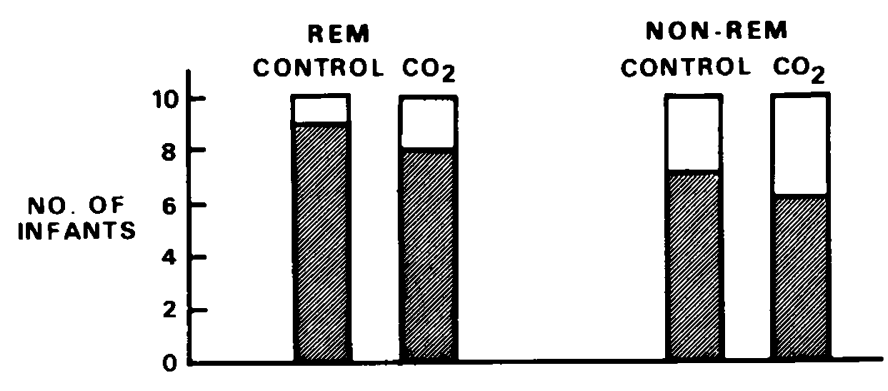

CHEST DISTORTION

TERM INFANTS

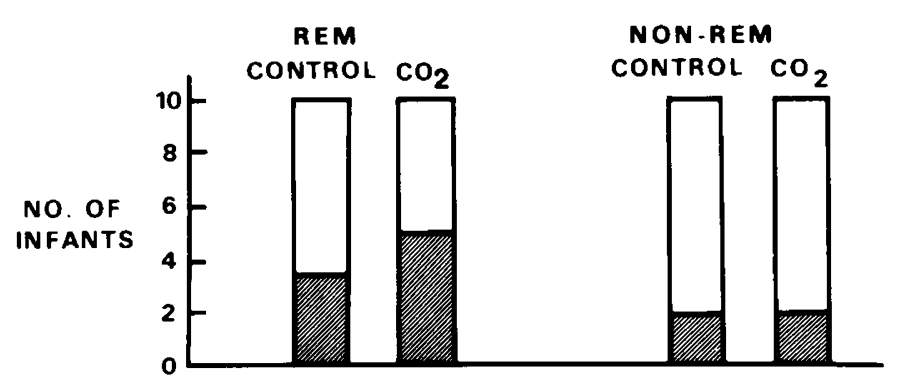

Fig. 2. Effect of $\mathrm{CO}_{2}$ on chest distortion during REM and non-REM sleep in preterm and term infants. The shaded area represents the number of infants with chest distortion. There is no difference in the prevalence of chest distortion before and during administration of $\mathrm{CO}_{2}$ in both sleep states. Note, however, that the prevalence of chest distortion is significantly higher in preterm than in term infants.

term infants, it was speculated that this was due to the highly compliant chest wall of these small infants rather than to sleep state.

These findings are contrary to previous observations that chest distortion is characteristic of REM sleep (17). They are more in agreement with data showing respiration in or out of phase in REM sleep (9). In some babies, sleep was tediously monitored as the infant switched from one state to the other on numerous occasions and a change could not be detected in the prevalence or magnitude of chest distortion. It is difficult, therefore, to reconcile these observations with those obtained previously (17). The clinical evidence that small babies breathe in a see-saw manner, and that this is not so frequent in term infants, lends support to the view that chest distortion is an attribute of the highly cartilagenous rib cage of preterm infants. Indeed, what is the diaphragm holding to in these infants, if not to a very pliable bone structure? Observations that static pulmonary compliance practically equals total static chest compliance is another evidence that rib cage serves the preterm little in terms of mechanical stability of the chest $(1,3)$. It is not surprising, therefore, that paradoxical movements of rib cage and abdomen are very common in preterm infants. The authors believe the immature structure of the rib cage as well as incompetence of chest wall musculature and reflexes are responsible for this.

Criticisms might be raised that preterm infants breathe only in REM sleep and, therefore, changes during non-REM sleep would be difficult to define. The authors had no such experience. It was found that hours of patient and careful monitoring of these infants in the research laboratory clearly demonstrated that these infants are not in REM sleep only. They are frequently in non-REM sleep and not unusually in perfectly quiet sleep $(15,21)$. These observations agree with previous sleep state studies $(10,15)$. Even supposing that such babies were in REM sleep state only, it would still be necessary to justify why term infants, who show clear epochs of non-REM and REM sleep, do not present a change in prevalence of chest distortion during both sleep states.

These findings of similar ventilatory response to $\mathrm{CO}_{2}$ during non-REM and REM sleep agree with observations made in newborn primates (12). They disagree, however, with observations in dogs (19) and in human neonates (6), which showed a decreased ventilatory response to $\mathrm{CO}_{2}$ during $\mathrm{REM}$ sleep. The reason for the discrepancies is not clear. It might be that there is not much to compare between an adult dog and a preterm human neonate, but the findings of Bryan et al. (6) cannot certainly be explained. If analog models of the respiratory control system were taken as designed by physicists and bioengineers, a slightly oscillating respiratory system during REM sleep to respond more to $\mathrm{CO}_{2}$ than a nonoscillatory system $(12,18)$ would be expected. It is difficult, therefore, to reconcile these differences at the present time and this subject needs further clarification.

In summary, these observations suggest that sleep state does not affect the prevalence of chest distortion or the ventilatory response to $\mathrm{CO}_{2}$. Increased prevalence of chest distortion in preterm as opposed to term infants may be better explained on the basis of highly immature and cartilagenous structure of the rib cage, as well as incompetence of chest wall muscles and reflexes.

\section{CONCLUSION}

In 10 preterm and 10 term infants, the effect of sleep state on chest distortion and on the ventilatory response to $\mathrm{CO}_{2}$ was assessed. It was found that chest distortion and ventilatory response to $\mathrm{CO}_{2}$ were independent of sleep state. Chest distortion, however, was more frequent in preterm than in term infants. The authors suggest that the increased prevalence of chest distortion in preterm infants is related to their highly compliant chest wall rather than to differences in sleep state.

\section{PRETERM INFANTS}

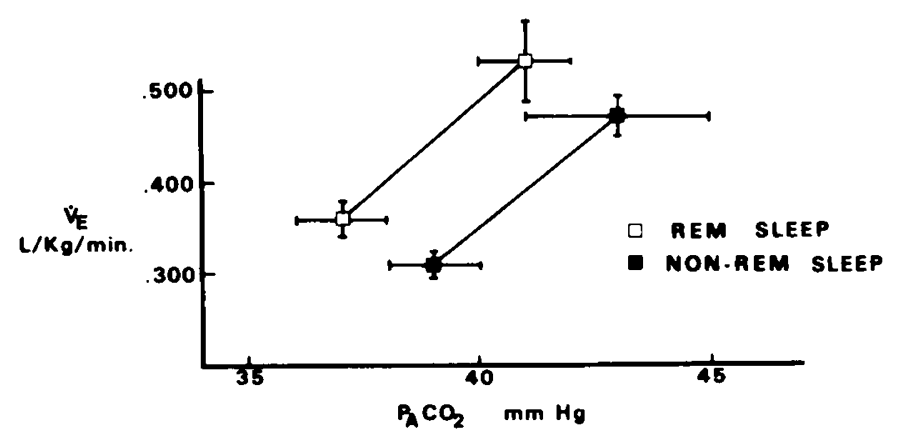

Fig. 3. Ventilatory response to $\mathrm{CO}_{2}$ in preterm infants during REM and non-REM sleep. There is no difference in slopes, but the intercept was shifted to the left during REM sleep.

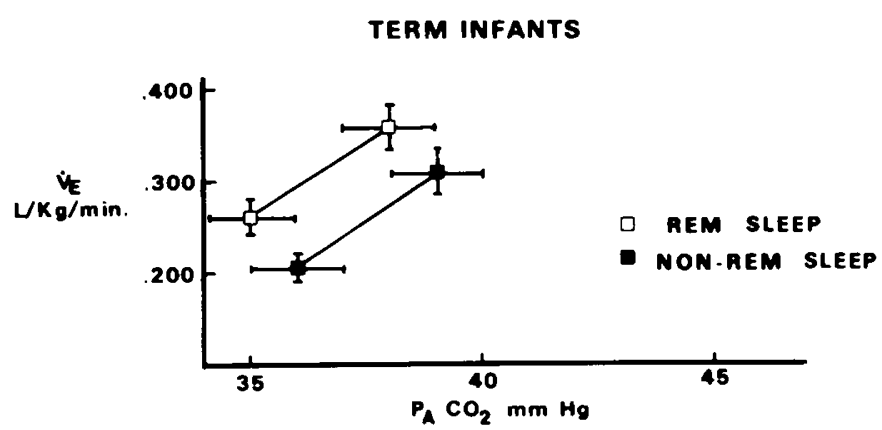

Fig. 4. Ventilatory response to $\mathrm{CO}_{2}$ in term infants during REM and non-REM sleep. There is no difference in slopes, but the intercept was significantly shifted to the left during REM sleep. 


\section{REFERENCES AND NOTES}

I. Agostoni, E.: Volume pressure relationships of the thorax and lung in the newborn. J. Appl. Physiol., 14: 909 (1959).

2. Aserinski, E., and Kleitman, N.: Regularly occurring periods of eye motility, and concomitant phenomena during sleep. Science, 118: 273 (1953).

3. Avery, M. E., and Cook. C. D.: Volume pressure relationships of lungs and thorax in fetal, newborn and adult goats. J. Appl. Physiol.. 16: 1034 (1961).

4. Birchfield. R. I., Sieker, H. O. and Heyman, A.: Alterations in respiratory function during natural sleep. J. Lab. Clin. Med., 54: 216 (1959).

5. Bolton. D. P. G., and Herman, S.: Ventilation and sleep state in the newborn. J. Physiol., London, 240: 67 (1974).

6. Bryan, M. H., Bryan, A. C., Hagan. R., and Gulston, G.: $\mathrm{CO}_{2}$ response in sleep state in infants. Clin. Res., 24: 698A (1976).

7. Bulow, K.: Respiration and wakefulness in man. Acta Physiol. Scand. (Suppl) 59 (209): I (1963)

8. Chase, M. H.: Central neural control of brainstem somatic reflexes during sleeping and waking. Advances in Sleep Research. Vol. I. Chap. 5, p. 251 (New York. Spectrum, 1974).

9. Frantz, I. D., Adler, S. M., Abroms, 1. F., and Thach, B. T.: Respiratory response to airway occlusion in infants: sleep-state and motivation. J. Appl. Physiol.. 41: 634 (1976)

10. Gabriel, M., Albani, M., and Schulte. F. J.: Apneic spells and sleep states in preterm infants. Pediatrics, 57: 142 (1976).

11. Grassino, A.: Influence of chest wall configuration on the static and dynamic characteristics of the contracting diaphragm. In: Loaded Breathing. L. D. Pengelly, A. S. Rebuck, and E. J. M. Campbell. (Longman Canada Limited. Toronto, 1974) p. 64

12. Crodins, F. S.: Control theory and biological systems. (New York, Columbia University Press, 1963).

13. Guthrie, R. O., Standaert, T. A., Hodson, W. A., and Woodrum, D. E.: Effects of sleep state on the ventilatory response to inhaled $\mathrm{CO}_{2}$ in the neonatal primate. Pediatr. Res. II: 534 (1977).

14. Hathorn, M. K. S.: The rate and depth of breathing in newborn infants in different sleep states. J. Physiol.. London, 243: 101 (1974).

15. Havlicek, V.. Childiaeva, R., and Chernick, V.: Ontogeny of EEG power characteristics of quiet sleep periodic cerebral rhythm in preterm infants. Neuropediatrie. 6: 151 (1975).
16. Jouvet, M.: Paradoxical sleep - a study of its nature and mechanisms. In: Progress in Brain Research. Vol. 18, Sleep Mechanisms. p. 20 (Amsterdam, Elsevier, 1965).

17. Knill R., Andrews, W., Bryan, A. C., and Bryan, M. H.: Respiratory load compensation in infants. J. Appl. Physiol., 40: 357 (1976).

18. Milhorn, H. R., Jr., Guyton. A. C.: Analog computer analysis of Cheyne-Stokes breathing. J. Appl. Physiol., 20: 238 (1965).

19. Phillipson, E. A., Kozar, L. F., Rebuck, A. S.. and Murphy, E.: Ventilatory and waking response to $\mathrm{CO}_{2}$ in sleeping dogs. Amer. Rev. Resp. Dis., II5 (2): 251 , (1977).

20. Phillipson, E. A., Murphy, E., and Kozar, L. F.: Regulation of respiration in sleeping dogs. J. Appl. Physiol., 40: 688 (1976).

21. Rechtshaffen, A., and Kales, A.: A Manual of Standardized Terminology, Techniques and Scoring System for Sleep Stages in Human Subjects. (Washington. D.C., United States Government Printing Office. National Institute of Health Publication 204, 1968).

22. Rigatto, $H$., and Brady, J. P.: A new nosepiece for measuring ventilation in preterm infants. J. Appl. Physiol., 32: 423 (1972).

23. Rigatto, H., and Brady, J. P.: Periodic breathing and apnea in preterm infants. I. Evidence for hyperventilation possibly due to central respiratory depression. Pediatrics, 50: 202 (1972).

24. Rigatto, H., Brady, J. P. and de la Torre Verduzco, R.: Chemoreceptor reflexes in preterm infants. II. The effect of gestational age on the ventilatory response to inhaled carbon dioxide. Pediatrics, 55: 614 (1975).

25. Rigatto, H., de la Torre Verduzco, R., Cates, D. B.: Effects of $\mathrm{O}_{2}$ on the ventilatory response to $\mathrm{CO}_{2}$ in preterm infants. J. Appl. Physiol., 39: 896 (1975).

26. The authors are indebted to Johanna Christensen and Betty Penney for typing and helping in the preparation of the manuscript.

27. Presented, in part, at the meeting of The Midwest Society for Pediatric Research, St. Louis, Missouri, November, 1977.

28. This research was supported by MRC of Canada grant MA-4980 and The Children's Hospital of Winnipeg Research Foundation. Inc.

29. Requests for reprints should be addressed to: Henrique Rigatto, M. D., Department of Pediatrics, WS108-700 William Avenue, Winnipeg, Manitoba, R3E 0 Z3.

30. Received for publication May 8, 1978.

31. Accepted for publication September 26, 1978. 